\title{
Preferência do pulgão-preto, Aphis craccivora Koch, a diferentes genótipos de feijão-de- corda, Vigna unguiculata (L.) Walp.
}

\author{
Black aphid, Aphis craccivora Koch, preference to different cowpea, Vigna unguiculata (L.) \\ Walp. Cultivars
}

João Gutemberg Leite Moraes ${ }^{I}$ Ervino Bleicher ${ }^{\mathrm{II}}$

RESUMO

Este trabalho foi desenvolvido visando a avaliar a resposta de cultivares de feijão-de-corda, Vigna unguiculata (L.) Walp., à presença do pulgão-preto (Aphis craccivora Koch). Os experimentos foram conduzidos de agosto a outubro de 2004, em casa-de-vegetação da Universidade Federal do Ceará (UFC). As cultivares foram: "Epace-10", "Epace-11", "Patativa”, "Pingo de Ouro", "Pitiúba”, "BR-10 Piauí", "BR12 Canindé”, "BR-14 Mulato” e "BR-17 Gurguéia”. O experimento constou de três ensaios, cada um com cinco tratamentos e seis repetições, sendo o delineamento estatístico inteiramente casualizado. Os genótipos foram cultivados em copos plásticos de $300 \mathrm{ml}$ e mantidos em gaiolas protegidas por tela antiafídeos. As plantas foram infestadas após doze dias do plantio através da liberação de cinco fêmeas adultas do pulgão-preto por planta. As avaliações foram realizadas após o terceiro e o quinto dia da infestação, constando da contagem direta das formas adulta e jovem do inseto presentes nas plantas. Os dados obtidos foram analisados através de análise de variância e pelo teste de Tukey em 5\% de probabilidade de erro. As cultivares "Epace-10" e "Patativa" foram as menos preferidas por A. craccivora.

Palavras-chave: resistência de plantas, afídeo, feijão-caupi.

\section{ABSTRACT}

This research was conducted with the intention of evaluating the response of different cowpea, Vigna unguiculata (L.) Walp, cultivars to the black aphid (Aphis craccivora Koch). The bioassays were conducted from August through October of 2004 in a greenhouse at the Ceará Federal University (UFC) campus. The cowpea cultivars used were: Epace-10, Epace11, Patativa, Pingo de Ouro, Pitiúba, BR-10 Piauí, BR-12 Canindé, BR-14 Mulato and BR-17 Gurguéia. Each assay had five treatments and six replications in a completely randomized block design. The genotypes were raised in a 300ml plastic cup and maintained in cages protected by an insect proof net. Plants were infested twelve days after planting with five adult females per plant. Evaluations were performed three and five days after infestation by visual counting of the adults and nymph forms present on the plants. A variance and Tukey analysis were done with the obtained data at a 5\% level of probability. The Epace 10 and Patativa cultivars were less preferred by $\boldsymbol{A}$. craccivora.

Key words: plant resistant, aphid, cowpea.

\section{INTRODUÇÃO}

O feijão-de-corda, ou feijão-caupi, Vigna unguiculata (L.) Walp., é considerado a principal fonte de proteína vegetal para a população rural da Região Nordeste do Brasil. Dentre os fatores limitantes ao seu cultivo, destacam-se as pragas e, dentre estas, o pulgão Aphis craccivora Koch (Hemiptera: Aphididae), que, além de causar danos diretos, ainda é responsável pela transmissão do Potyvirus, Cowpea Aphid-Borne Virus (CpAMV), amplamente disseminado pelo Estado do Ceará, e do Blackeye Mosaic Virus (BICpMV) (LIMA et al., 1981).

Dentre os métodos de controle de viroses transmitidas por essa espécie de pulgão, é citado o uso de cultivares de feijão-de-corda resistentes, como os novos materiais lançados pela Embrapa Meio-Norte. No entanto, pouco se sabe sobre o efeito direto do pulgão-preto sobre as cultivares existentes. Em relação à resistência de cultivares de feijão-de-corda ao $\boldsymbol{A}$. craccivora, é fundamental uma avaliação de germoplasma frente às populações do afídeo no Brasil. Isso deveria ser feito em razão do marcante efeito do ambiente na resistência da planta, como mostrou CHALFANT (1985), ao relatar que cultivares resistentes ao A. craccivora na África não tinham o mesmo comportamento na Geórgia, Estados Unidos (SANTOS \&QUINDERÉ, 1988).

IPrograma de Pós-graduação em Agronomia/Fitotecnia, Universidade Federal do Ceará (UFC), Campus do Pici, 60451-970, Fortaleza, CE, Brasil. E-mail: j_gutemberg@yahoo.com.br. Autor para correspondência.

IIDepartamento de Fitotecnia, UFC, Fortaleza, CE, Brasil. 
Aproximadamente 200 cultivares de feijãode-corda foram selecionadas para estudos de resistência ao $\boldsymbol{A}$. craccivora. Dessas, três cultivares mostraram-se resistentes no oeste da África, porém foram altamente suscetíveis no sul dos Estados Unidos. Quatro outras cultivares inibiram o crescimento de populações do inseto no sul dos EUA. Ambos os resultados foram obtidos em condições de campo e casa-de-vegetação (MESSINA et al., 1985). Essas discrepâncias podem estar ligadas à existência de biotipos de pulgão-preto, pois, segundo SAXENA \& BARRION (1987), só na Nigéria são encontrados cinco biotipos.

O presente trabalho teve como objetivo selecionar cultivares de feijão-de-corda com maior resistência à presença do pulgão-preto dentre as cultivares mais utilizadas na Região Nordeste do Brasil.

\section{MATERIAL E MÉTODOS}

Os trabalhos foram realizados em casa-devegetação do Departamento de Fitotecnia do Centro de Ciências Agrárias (CCA) da Universidade Federal do Ceará (UFC), localizada no Campus do Pici, em Fortaleza, de agosto a outubro de 2004. As médias de temperaturas, mínima e máxima, na casa-de-vegetação, no período da pesquisa, foram de $26,5^{\circ} \mathrm{C}$ e $30,8^{\circ} \mathrm{C}$, respectivamente, e a umidade relativa foi de $70 \pm 10 \%$.

Foram utilizadas nove cultivares de feijãode-corda: "Epace-10”, obtida da linha CNCx166-8E, do cruzamento de "Seridó” com "TVu 1888”; "Epace-11”, obtida da linha CNCx164-03G, resultante do cruzamento de "Seridó” com “CNCx50-03E”; "Patativa”, constituída da população original da linha EVx92-49E, que resultou de seleção individual, na geração $\mathrm{F} 5$, dentro da população do cruzamento EVx92 [CNC 1735 x EVx63 (CNCx926-4F x Paulista)]; "Pingo de Ouro", cultivar de produtores; "Pitiúba”, seleção massal em cultivares de produtores (utilizada como cultivar de referência); "BR10 Piaú́," obtida do cruzamento entre a cultivar "CNC 0434”, oriunda do International Institute of Tropical Agriculture (IITA), na Nigéria, e o cultivar “TVu 612”, também procedente do IITA; "BR-12 Canindé”, da linhagem TEx 11-99 H/SM, que foi obtida do cruzamento entre os genótipos TVu 612 e CNC 0434; "BR-14 Mulato”, originária da população CNCx 249-313F, obtida do cruzamento entre os genótipos CNC 0434 e CNCx 27-2E; “BR-17 Gurguéia”, corresponde à linhagem TE86-75-37E.1, obtida do cruzamento entre as cultivares “BR-10 Piaú,” e “CE-315” (TVu 2331). As cinco primeiras cultivares foram provenientes do Banco Ativo de Germoplasma (BAG) do CCA da UFC e da extinta Empresa de Pesquisa Agropecuária do Ceará (EPACE), e as demais da Embrapa Meio-Norte.
O trabalho constou de três ensaios. No primeiro, foram utilizados as cinco primeiras cultivares citadas anteriormente, enquanto que, no segundo, utilizaram-se as quatro últimas cultivares citadas mais a cultivar "Pitiúba”. No último, realizou-se a validação da metodologia dos dois ensaios iniciais. Para o ensaio de validação da metodologia, foram eleitas uma cultivar suscetível e uma resistente, selecionadas mediante os resultados encontrados nos dois primeiros ensaios. A cultivar "Pitiúba" foi utilizada como referência de suscetibilidade, enquanto a "Epace-10" como referência de não-preferência.

As plantas foram cultivadas em copos descartáveis com 300ml de capacidade. Como substrato, utilizou-se: solo (50\%), húmus de minhoca (30\%) e substrato comercial (20\%). Foram colocadas duas sementes por copo. Após três dias da germinação, foi efetuado o desbaste de uma plântula, permanecendo somente uma por recipiente. A irrigação e outros cuidados necessários ao bom desenvolvimento das plantas foram realizados diariamente.

O delineamento para cada ensaio foi o inteiramente casualizado, com cinco tratamentos e seis repetições, sendo a unidade experimental constituída de uma planta por copo. Foram utilizadas duas gaiolas para cada ensaio, sendo que cada uma continha quinze plantas.

Aos doze dias após o plantio, as plantas foram devidamente distribuídas sobre as bancadas de maneira a não se tocarem, para que fosse realizada a infestação. Em seguida, foram postas em duas gaiolas protegidas com tela antiafídeos com as seguintes dimensões: 1,0m x 1,0m x 0,5m. Fêmeas adultas ápteras foram cuidadosamente selecionadas e retiradas, com o auxílio de um pincel, de plantas de feijão-de-corda de uma criação do inseto (população Campus do Pici) que era mantida em outra casa-de-vegetação. Posteriormente, foram colocadas cinco dessas fêmeas sobre cada planta. Três dias após a infestação, quantificou-se o número de insetos adultos presentes em cada cultivar, retirando-os da planta. Passados cinco dias, avaliou-se, por planta, o número de ninfas, sem separá-las por instar. Os dados foram transformados pela fórmula $(x+0,5)^{1 / 2}$ e submetidos a uma análise de variância, sendo as médias comparadas pelo teste de Tukey a 5\% de probabilidade de erro.

\section{RESULTADOS E DISCUSSÃO}

No primeiro ensaio, a "Epace-10" foi a cultivar que apresentou menor número de adultos por planta (Tabela 1). Sugere-se que este genótipo tenha exercido efeito de antixenose ou não-preferência sobre 
Tabela 1 - Número médio de adultos e ninfas de Aphis craccivora Koch, 1854, em cultivares de Vigna unguiculata L. (Walp), contados aos três e cinco dias da infestação, respectivamente. Fortaleza, CE. 2004.

\begin{tabular}{lcc}
\hline Tratamentos & $\begin{array}{c}\mathrm{N}^{\circ} \text { de adultos por } \\
\text { planta }\end{array}$ & $\begin{array}{c}\mathrm{N}^{\mathrm{o}} \text { de ninfas por } \\
\text { planta }\end{array}$ \\
\hline Epace-11 & $3,67 \mathrm{a}$ & $124,33 \mathrm{a}$ \\
Pitiúba & $5,17 \mathrm{a}$ & $118,50 \mathrm{a}$ \\
Pingo de Ouro & $3,67 \mathrm{ab}$ & $96,33 \mathrm{a}$ \\
Patativa & $0,67 \mathrm{bc}$ & $39,83 \mathrm{~b}$ \\
Epace-10 & $0,33 \mathrm{c}$ & $20,50 \mathrm{~b}$ \\
CV $(\%)$ & 19,91 & 29,58 \\
\hline
\end{tabular}

1 - As médias na coluna não seguidas da mesma letra diferem estatisticamente entre si pelo teste de Tukey em nível de 5\% de probabilidade de erro.

os insetos, sendo selecionado, portanto, como cultivar resistente para a validação posterior da metodologia adotada. Deve ser destacado o comportamento da cultivar "Patativa", a qual apresentou o mesmo comportamento da “Epace-10” quanto à resistência ao afídeo, não sendo observada diferença estatística entre as duas cultivares (Tabela 1).

As cultivares “Epace-11”, "Pitiúba” e "Pingo de Ouro" foram as mais preferidas pela praga, sendo que a "Pitiúba" chegou a superar o número de insetos colocados por ocasião da infestação, com 5,17 adultos por planta. A condição de livre escolha das fêmeas ápteras permitiu que houvesse o deslocamento das mesmas entre plantas no interior das gaiolas.

As formas ápteras do Aphis craccivora são atraídas por colônias de até 10 insetos e repelidas por grupos maiores (PETTERSON et al., 1998). Assim sendo, os cinco insetos inicialmente colocados deveriam permanecer juntos, a não ser que algum estímulo mais forte iniciasse um comportamento de dispersão. Esse estímulo poderia ser o odor das cultivares, pois, como alertam os autores anteriormente citados, o pulgão-preto pode distinguir odores entre espécies de plantas.

Para o número de ninfas avaliado neste trabalho, não foram realizados estudos específicos para determinar o mecanismo de resistência desenvolvido pelas cultivares. Entretanto, pode ser relatado que o número de ninfas encontrado por planta foi oriundo dos insetos adultos liberados por planta. Isso demonstra que a cultivar que apresentou maior número de ninfas foi aquela que proporcionou melhores condições de desenvolvimento para o inseto adulto. Estudando a resistência de cultivares de feijão-decorda, SINGH (1990) identificou cinco cultivares resistentes, sendo a causa da resistência do tipo antibiose o que causa a redução no número de descendentes, ao contrário do efeito observado neste ensaio. SINGH \& NTARE (1985) e VAN EMDEN (1991) afirmaram que a resistência genética de feijão-de-corda ao A. craccivora é um fator regido por um gene simples dominante.

As cultivares do segundo ensaio (Tabela 2) não apresentaram diferença. Os valores indicam uma provável proximidade genética entres as cultivares, as quais possuem relativo grau de parentesco. As cultivares citadas na tabela 2 não diferiram da cultivar "Pitiúba”, a qual foi selecionada como referência de susceptibilidade à presença do pulgão-preto.

Muito embora os resultados mostrados nos materiais da Embrapa Meio-Norte ("BR-10 Piauí", "BR12 Canindé”, “BR-14 Mulato” e "BR-17 Gurguéia”) tenham sido semelhantes para as condições locais, fazse necessário o teste dos mesmos sob outras condições de ambiente e frente a outras populações desse afídeo, conforme citaram SANTOS \& QUINDERÉ (1988). Segundo SAXENA \& BARRION (1987), são encontrados na Nigéria cerca de cinco biotipos do $\boldsymbol{A}$. craccivora. Dessa forma, estudos direcionados à identificação de possíveis biotipos de afídeos, nas regiões do Brasil onde a praga é importante, e sua relação com os genótipos avaliados nesta pesquisa, podem melhor caracterizar níveis de resistência ou de suscetibilidade para as condições locais.

Os resultados relativos à validação da metodologia, ou contra-prova, confirmaram os resultados dos dois ensaios iniciais (Tabela 3). Baseado no exposto, o genótipo "Epace-10" confirmou ser o menos preferido. A cultivar "Pitiúba”, utilizada como referência nos três ensaios, mostrou ser um bom padrão de suscetibilidade para este tipo de ensaio.

Tabela 2 - Número médio de adultos e ninfas de Aphis craccivora Koch, 1854, em cultivares de Vigna unguiculata L. (Walp), contadas aos três e cinco dias da infestação, respectivamente. Fortaleza, CE. 2004.

\begin{tabular}{lcl}
\hline Tratamentos & $\begin{array}{c}\mathrm{N}^{\circ} \text { de adultos por } \\
\text { planta }\end{array}$ & $\begin{array}{c}\mathrm{N}^{\circ} \text { de ninfas por } \\
\text { planta }\end{array}$ \\
\hline Pitiúba & $4,17 \mathrm{a}$ & $130,33 \mathrm{a}$ \\
BR-12 Canindé & $2,67 \mathrm{a}$ & $125,83 \mathrm{a}$ \\
BR-17 Gurguéia & $4,50 \mathrm{a}$ & $119,17 \mathrm{a}$ \\
BR-14 Mulato & $3,33 \mathrm{a}$ & $101,50 \mathrm{a}$ \\
BR-10 Piauí & $2,00 \mathrm{a}$ & $72,67 \mathrm{a}$ \\
CV $(\%)$ & 23,61 & 26,37 \\
\hline
\end{tabular}

1 - As médias na coluna não seguidas da mesma letra diferem estatisticamente entre si pelo teste de Tukey em nível de 5\% de probabilidade de erro. 
Tabela 3 - Número médio de adultos e ninfas de Aphis craccivora Koch, 1854, em genótipos de Vigna unguiculata L. (Walp), contados aos três e cinco dias da infestação, respectivamente. Fortaleza, CE. 2004.

\begin{tabular}{lcl}
\hline Tratamentos & $\begin{array}{c}\text { No de adultos por } \\
\text { planta }\end{array}$ & $\begin{array}{c}\mathrm{N}^{\circ} \text { de ninfas por } \\
\text { planta }\end{array}$ \\
\hline Epace-11 & $3,83 \mathrm{a}$ & $176,17 \mathrm{a}$ \\
Pitiúba & $4,50 \mathrm{a}$ & $175,83 \mathrm{a}$ \\
BR-12 Canindé & $4,63 \mathrm{a}$ & $122,17 \mathrm{a}$ \\
BR-10 Piauí & $3,67 \mathrm{a}$ & $118,33 \mathrm{a}$ \\
Epace-10 & $0,67 \mathrm{~b}$ & $17,17 \mathrm{~b}$ \\
CV (\%) & 12,87 & 16,32 \\
\hline
\end{tabular}

1 - As médias na coluna não seguidas da mesma letra diferem estatisticamente entre si pelo teste de Tukey em nível de $5 \%$ de probabilidade de erro.

\section{CONCLUSÕES}

Os genótipos “Epace-10" e "Patativa” são os menos preferidos pelo pulgão-preto, apresentando como possível mecanismo de resistência para adultos a antixenose e/ou a antibiose. A metodologia utilizada é eficaz para a triagem de genótipos de feijão-de-corda frente à espécie $A$. craccivora.

\section{AGRADECIMENTOS}

Ao Programa de Educação Tutorial, PETAgronomia, pela bolsa concedida aos autores. Ao Dr. Francisco Rodrigues Freire Filho (Embrapa Meio-Norte) e à Dra. Elizita Maria Teófilo (Departamento de Fitotecnia, CCA, UFC), pela cessão do material genético. À bibliotecária da Embrapa Agroindústria Tropical, Rita de Cássia Costa Cid, pela valiosa ajuda na comutação de artigos científicos citados nesta pesquisa.

\section{REFERÊNCIAS}

CHALFANT, R.B. Entomological research on cowpea pests in the USA. In: SINGH, S.R.; RACHIE, K.O. (Ed.). Cowpea research, production and utilization. Chichester: Jonh Wiley, 1985. p.267-274.

LIMA, J.A.A. et al. Propriedades biológicas sorológicas, citológicas e sorológicas de um potyvirus isolado de feijão-decorda no Ceará. Fitopatologia Brasileira, v.6, p.205-216, 1981.

MESSINA, F.J. et al. Resistance to Aphis craccivora (Homoptera: Aphididae) in selected varieties of cowpea. Journal of Entomological Science, v.20, p.263-269, 1985.

PETTERSON, J. et al. The cowpea aphid, Aphis craccivora, has plant odours pheromones. Entomologia Experimentalis et Applicata, v.88, p.177-184, 1998.

SANTOS, J.H.R. dos. QUINDERÉ, M.A.W. Distribuição, importância e manejo das pragas do caupi no Brasil. In: ARAÚJO, J.P.P. de; WATT, E.E. (Org.). O Caupi no Brasil. Brasília: EMBRAPA, 1988. Cap.21, p.619-621.

SAXENA, R.C; BARRION, A.A. Biotypes of insects pests of agricultural crops. Insect Science and its Application, v.8, p.453-458, 1987.

SINGH, S.R. (Ed.). Insect pests of tropical food legumes. Chichester/Eng.: John Wiley\&Sons, 1990. 451p.

SINGH, S.R.; NTARE, B.R. Development of improved cowpea variets in Africa. In: S.R. SINGH; K.O.; RACHIE, K.O. (Ed.). Cowpea research, production and utilization. Chichester: Jonh Wiley, 1985. p.106-115.

VAN EMDEN, H.F. The role of host plant resistance in insect pest mis-management. Bulletin of Entomological Research, v.19, p.3-4, 1991. 